This item was submitted to Loughborough's Research Repository by the author.

Items in Figshare are protected by copyright, with all rights reserved, unless otherwise indicated.

\title{
Effect of acute and regular exercise on growth hormone secretagogue receptor-1a expression in human lymphocytes, $\mathrm{T}$ cell subpopulation and monocytes
}

\section{PLEASE CITE THE PUBLISHED VERSION}

http://dx.doi.org/10.1016/j.bbi.2013.09.017

\section{PUBLISHER}

(C) Elsevier

\section{VERSION}

AM (Accepted Manuscript)

\section{LICENCE}

CC BY-NC-ND 4.0

\section{REPOSITORY RECORD}

Bishop, Nicolette, Harumi Hayashida, Megan Clark, Charlotte Coombs, Sean Miller, and David J. Stensel. 2019. "Effect of Acute and Regular Exercise on Growth Hormone Secretagogue Receptor-1a Expression in Human Lymphocytes, T Cell Subpopulation and Monocytes". figshare. https://hdl.handle.net/2134/13415. 
This item was submitted to Loughborough's Institutional Repository (https://dspace.lboro.ac.uk/) by the author and is made available under the following Creative Commons Licence conditions.

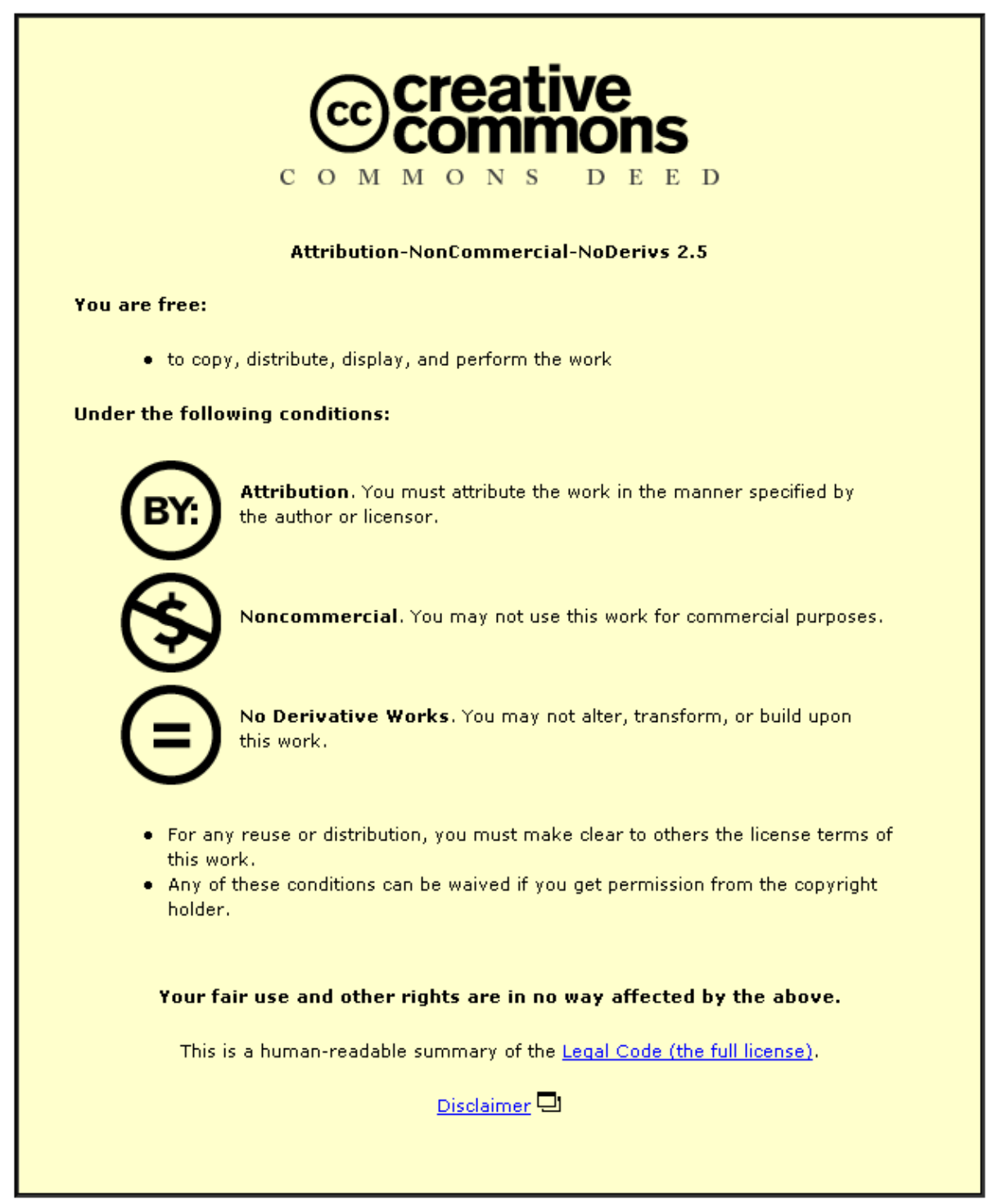

For the full text of this licence, please go to: http://creativecommons.org/licenses/by-nc-nd/2.5/ 
Effect of acute and regular exercise on growth hormone secretagogue receptor-1a expression in Human lymphocytes, $T$ cell subpopulation and monocytes.

Nicolette C Bishop, Harumi Hayashida, Megan Clark, Charlotte Coombs, Sean Miller and David J Stensel.

School of Sport, Exercise and Health Sciences, Loughborough University, Loughborough, UK.

Address for correspondence

Nicolette C Bishop

School of Sport, Exercise and Health Sciences

Loughborough University

Loughborough

Leicestershire

LE11 3TU

Email: n.c.bishop@lboro.ac.uk

Tel: + 441509226385

Fax: +44 1509226301

Conflict of interest statement: All authors declare that there are no conflicts of interest. 


\section{ABSTRACT}

The orexigenic peptide hormone ghrelin exerts potent inhibitory effects on pro-inflammatory cytokine release via the growth hormone secretagogue receptor-1a (GHS-R1a) on T cells and monocytes. As such, ghrelin is a promising therapeutic agent for the treatment of inflammatory conditions, but these effects depend on the availability of GHS-R1a. The aim of this study was to determine the effect of acute exercise on GHS-R1a expression on circulating CD14+ monocytes, total lymphocytes and CD3+ $\mathrm{T}$ cells. Nine male clubstandard cyclists cycled for $1 \mathrm{~h}$ at $75 \% \dot{\mathrm{V}} \mathrm{O}_{2 \text { peak }}(\mathrm{EX})$ or rested (REST) in a randomised crossover design. Compared with the equivalent times in REST, the concentration of circulating GHS-R1a+ lymphocytes and monocytes was higher in EX at immediately and 1 and 2 h postexercise (all $p<.05$ ). The concentration of CD3+GHS-R1a+ cells was higher in EX than in REST immediately post-exercise only (258 (203) cells. $\mu \mathrm{l}^{-1}$ vs. 62 (42) cells. $\left.\mu \mathrm{l}^{-1}, p<.05\right)$. Density of GHS-R1a receptor expression was unaffected by trial or time. Comparison of active participants at rest with 7 age-, sex- and BMI-matched sedentary controls revealed a higher concentration of GHS-R1a+ lymphocytes in active males $(p<.05)$. These findings suggest a preferential recruitment of specific cell subpopulations expressing GHS-R1a into the peripheral circulation with acute and regular exercise. Given that the anti-inflammatory effects of ghrelin depend on the availability of GHS-R1a, the preferential recruitment of subpopulations with high anti-inflammatory potential found here add a novel aspect to the potential mechanisms by which exercise acts to reduce pro-inflammatory cytokine levels.

Key words: T cell, monocyte, ghrelin, inflammatory, growth hormone secretagogue receptor 


\section{Introduction}

There is increasing evidence of the coupling of immune status to the metabolic system (Dixit and Taub, 2005; Karalis et al., 2009; Odegaard and Chawla, 2013). This communication is mediated via a complex array of cytokines, hormones and neuropeptides. Ghrelin, an orexigenic peptide hormone, is predominantly produced by the X/A-like cells within the oxyntic mucosa of the stomach and has been primarily studied in relation to the regulation of food intake and its action in stimulating growth hormone release from the anterior pituitary gland. Aside from these well-studied effects, ghrelin is now known to play a key role in the regulation of inflammation, with reports of inhibitory effects of the acylated (but not des-acylated) isoform of ghrelin on IL-1 $\beta$, IL-6 and TNF- $\alpha$ mRNA and protein expression in both human and rodent T cells and monocytes in vivo and in vitro (Dixit et al., 2004; DeBoer et al., 2008; Waseem et al., 2008). Acylated ghrelin also attenuates leptininduced pro-inflammatory cytokine responses in human monocytes and T cells (Dixit et al., 2004). These cytokines are believed to mediate loss of appetite or anorexia commonly associated with inflammation, injury or illness (Kelley et al., 2003) and their overexpression can lead to a catabolic state and cachexia (Dixit and Taub, 2005). With this in mind, acylated ghrelin has been proposed as a promising therapeutic agent for the treatment of a host of cachectic and other chronic inflammatory conditions including cancer cachexia, cardiovascular, respiratory and kidney diseases, inflammatory bowel diseases and ageassociated inflammation (Baatar et al., 2011; DeBoer, 2011; Steinman and DeBoer, 2013). However, while initial findings have been promising, the safety of long-term ghrelin treatment is still unknown (Strasser et al., 2008; DeBoer, 2011).

The effects of acylated ghrelin on immune cell cytokine release are dependent on the availability of its target receptor, the growth hormone secretagogue receptor-1a (GHS-R1a) 
(Dixit et al., 2004). GHS-R1a has been demonstrated on various immune cell subsets, including T cells, B cells, monocytes and neutrophils (Hattori et al., 2001; Dixit et al., 2004). Expression of GHS-R1a mRNA and protein by human T cells is increased by 3-4 fold upon activation with the mitogens phytohemagglutinin and concanavalin A, with similar results seen in LPS-stimulated monocytes (Dixit et al., 2004). Considering that acute exercise at intensities of at least $\sim 65-70 \% \dot{\mathrm{V}} \mathrm{O}_{2 \max }$ is associated with an increased proportion of circulating activated T cells and monocytes (Woods et al., 2000; Walsh et al., 2011) it is plausible that exercise could promote an increase in the circulating availability of GHS-R1a on peripheral blood mononuclear cells (PBMCs). However, to date any effect of exercise on the expression of GHS-R1a on PBMCs has not been investigated.

The purported 'anti-inflammatory' benefits of regular exercise have been the focus of much recent investigation. Mechanisms suggested to be involved in the lowering of circulating levels of pro-inflammatory cytokines associated with a more active lifestyle include muscle myokine release, alterations in circulating $\mathrm{T}$ cell and monocyte phenotype and altered macrophage phenotype within adipose tissue (Gleeson et al., 2011). It is an intriguing possibility that GHS-R1a expression on immune cells is an additional mechanism by which exercise regulates inflammatory cytokine production. Additionally, participation in regular physical activity to dampen the expression of pro-inflammatory cytokines is also advocated in the treatment of many of the clinical conditions for which the efficacy of ghrelin therapy is also proposed. Considering that the actions of acylated ghrelin on immune cell cytokine release are dependent on ligation with GHS-R1a, investigation of any interaction between exercise and immune cell GHS-R1a expression will provide valuable information concerning the potential for exercise to enhance the therapeutic benefits of acylated ghrelin treatment. 
Therefore, the aim of the present study was two-fold: firstly to determine the effect of an acute bout of exercise on the expression of GHS-R1a on total circulating lymphocytes, CD3+ T cells and CD14+ monocytes in active individuals and secondly, to investigate any differences in these measures between regularly active and sedentary individuals at rest.

\section{METHODS}

\section{Participants}

Nine male non-elite club-standard cyclists (mean \pm SD: age $24 \pm 2$ years; height $178 \pm 6 \mathrm{~cm}$; body mass $72.4 \pm 5.2 \mathrm{~kg}$; body mass index (BMI) $22.8 \pm 1.9$ kg.m ${ }^{-2}$; $\dot{\mathrm{VO}}_{\text {2peak }} 65.0 \pm 8.5$ $\left.\mathrm{ml} . \mathrm{kg}^{-1} \cdot \mathrm{min}^{-1}\right)$ and 7 sedentary males $(23 \pm 2$ years, height $181 \pm 9 \mathrm{~cm}$, weight $75.4 \pm 13.0 \mathrm{~kg}$, BMI $23.0 \pm 2.3 \mathrm{~kg} . \mathrm{m}^{-2}$ ) volunteered to participate in the experimental trials. All participants were informed of the rationale for the study and, where applicable, the nature of the exercise tests to be performed before providing written informed consent. The study protocol was approved by the local University Ethical Committee. Participants were required to complete a comprehensive health-screening questionnaire prior to each visit to the laboratory and did not report any symptoms of infection and had not taken any medication during the 6 weeks prior to the study, nor were they currently on medication. All participants were non-smokers. Sedentary participants were defined as engaging in less than 30 min of moderate- or vigorous-intensity exercise per day and had done so for at least 3 months. All participants completed the short version of the validated International Physical Activity Questionnaire (IPAQ; http://www.ipaq.ki.se/downloads.htm; Craig et al., 2003) within a 2-week window either side of participating in the study to give an indication of activity levels.

Acute Exercise: experimental design.

The active participants attended the laboratory on four occasions; 2 preliminary visits (initial assessment of $\dot{\mathrm{V}} \mathrm{O}_{2 \text { peak }}$ and familiarisation to the main exercise trial) and 2 experimental trials 
(exercise trial: EX and resting trial: REST). Participants completed EX and REST in a randomised order at least 7 days apart.

\section{Preliminary exercise testing}

Approximately 1 week before the beginning of the main study each participant performed a continuous incremental exercise test on an electromagnetically braked cycle ergometer (Lode Excalibur Sport, Groningen, The Netherlands) to volitional exhaustion to determine peak oxygen uptake ( $\dot{\mathrm{V}} \mathrm{O}_{\text {2peak }}$ ). Participants began cycling at $95 \mathrm{~W}$, with increments of $35 \mathrm{~W}$ every 3 min until volitional fatigue. Samples of expired gas were collected in Douglas bags during the $3^{\text {rd }}$ min of each work rate increment and heart rates were measured continuously using short-range radio telemetry (Polar FSI, Polar Electro Ltd, Oy, Finland). A paramagnetic oxygen analyser (Servomex 1420B, Crowborough, UK) and an infrared carbon dioxide analyser (Servomex 1415B) were used along with a dry gas meter (Harvard Apparatus, Edenbridge, UK) for determination of $\dot{\mathrm{V}} \mathrm{E}, \dot{\mathrm{V}} \mathrm{O}_{2}$ and $\dot{\mathrm{V}} \mathrm{CO}_{2}$. Gas analysers were calibrated according to the manufacturer's instructions using a zero gas $\left(100 \% \mathrm{~N}_{2}\right)$, a calibration mix $\left(16 \% \mathrm{O}_{2}\right.$ and $\left.4 \% \mathrm{CO}_{2}\right)$ and atmospheric air. The work rate equivalent to $75 \%$ $\dot{\mathrm{V}} \mathrm{O}_{2 \text { peak }}$ was interpolated from the $\dot{\mathrm{V}} \mathrm{O}_{2}$-work rate relationship. At this visit, height was measured to the nearest $0.1 \mathrm{~cm}$ using a stadiometer (Seca, Hamburg, Germany) and body mass was measured to the nearest $0.01 \mathrm{~kg}$ using an electronic scale (Avery, Birmingham, UK).

Participants returned to the laboratory within 7 days of the $\dot{\mathrm{V}} \mathrm{O}_{2 \text { peak }}$ test at a time of their choosing in order to acquaint themselves with the exercise trial procedures. During this familiarisation trial, participants cycled on a stationary electrically braked cycle ergometer for

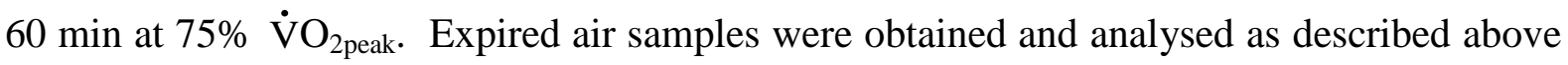


after the first $15 \mathrm{~min}$ and at 15-min intervals thereafter in order to ensure that the participants were exercising at the required intensity. If the subject was exercising at $\pm 5 \%$ of the required intensity the work rate was adjusted accordingly; this occurred within 5 min of expired air sample collection. Heart rates were monitored throughout this familiarisation trial.

\section{Main experimental trials}

In an effort to standardise their nutritional status, participants were asked to eat the same foods and drinks during the 24-h prior to both experimental trials. Participants were also asked to refrain from strenuous exercise, caffeine and alcohol during the 24-h before both main trials. For both trials participants arrived at the laboratory at 09:30 $\mathrm{h}$ following an overnight fast of at least $10 \mathrm{~h}$. In EX only, participants were then required to empty their bladder before body mass (in shorts only) was recorded. Subsequently, participants sat quietly for $10 \mathrm{~min}$ before an initial (pre-exercise) blood sample was collected from a superficial forearm vein. At 10:00 participants began cycling on a stationary electrically braked cycle ergometer for $60 \mathrm{~min}$ at $75 \% \dot{\mathrm{VO}}_{2 \text { peak. }}$ Expired air samples and heart rate were monitored as in the familiarisation trial. Participants were allowed to consume water ad libitum for the duration of the main trials. Further blood samples were collected immediately (11:00) and at $1 \mathrm{~h}(12: 00)$ and $2 \mathrm{~h}$ (13:00) post exercise. No further food or fluid intake was allowed until after the final blood sample had been collected. Body mass (in shorts only) was recorded after the immediately post-exercise blood sample had been collected.

In REST, participants rested quietly in the laboratory for $3 \mathrm{~h}$, sitting reading, writing or working at a computer. Blood samples were taken at the same time of day as in EX (10:00, 11:00, 12:00 and 13:00). Mean \pm SD laboratory conditions for all trials were $22.8 \pm 0.7^{\circ} \mathrm{C}$ and $42 \pm 4 \%$ relative humidity. 


\section{Blood analyses}

Blood samples were collected into three evacuated blood collection tubes, two containing EDTA (1.6 mg EDTA/mL blood) and one containing sodium heparin (16 IU heparin/mL blood). One of the tubes containing EDTA (7.5 ml) was used to determine total numbers of lymphocytes and monocytes and haematocrit and haemoglobin levels using a haematology analyser ( $\mathrm{A}^{\mathrm{C}} \cdot \mathrm{T}^{\mathrm{TM}}$ 5diff analyser, Beckman Coulter, High Wycombe, UK). The intra-assay coefficient of variation for all measured variables was less than $3.0 \%$. Plasma volume changes were assessed from the haemoglobin and haematocrit values according to Dill and Costill (1974). All blood cell data were adjusted for plasma volume change relative to the first blood sample for each participant for each trial.

Assessment of GHS-R1a expression on total lymphocytes, T cells and monocytes.

Receptor quantification on circulating total lymphocytes, CD3+ $\mathrm{T}$ cells and CD14+ monocytes was determined by flow cytometry in heparinised whole blood, using Pharmingen monoclonal antibodies purchased from Becton Dickinson Biosciences, Oxford, UK and GHS-R1a receptor and IgG secondary antibody from Santa Cruz Biotechnology, Santa Cruz, CA. A whole blood staining method was employed in order to minimally perturb the in vivo physiological status of GHS-R1a. For each sample, duplicate $100 \mu \mathrm{l}$ aliquots of heparinised whole blood were labelled with the monoclonal antibodies fluorescein isothiocyanate (FITC) conjugated anti-CD3 and phycoerythrin (PE) conjugated anti-CD14. $25 \mu \mathrm{l}$ anti-GHS-R1a was subsequently added to one of the tubes only; the other tube acted as the negative control. All tubes were incubated on ice for $20 \mathrm{~min}$, after which the erythrocytes were lysed with FACS $^{\mathrm{TM}}$ Lyse (Becton Dickinson Biosciences, Oxford, UK) and incubated for a further 10 min at room temperature in the dark. Samples were centrifuged, the supernatant aspirated 
and the cells resuspended. $25 \mu$ l allophycocyanin (APC) conjugated anti-donkey IgG F(ab’) 2 diluted 1:100 in HBSS was then added to all tubes before a further incubation for 10 min in the dark at room temperature. Cells were then washed in ice cold PBS containing 0.1\% bovine serum albumin and $2 \mathrm{mM}$ EDTA (PBS/BSA/EDTA) before the leukocytes were resuspended in $400 \mu \mathrm{l}$ PBS/BSA/EDTA.

Three-colour flow cytometric analysis was carried out using a FACSCalibur flow cytometer with CellQuest analysis software (Becton Dickinson, Oxford, UK). An unstained sample was used to set quadrant boundaries to allow accurate acquisition of stained samples. 100,000 events were acquired per analysis. Side scatter versus forward scatter plots were used to gate on the lymphocyte population. The percentage of gated lymphocytes expressing CD3 was derived from analysis of FL1 (CD3-FITC) versus FL4 (IgG-APC) dot plots. CD3+ cells were gated into a separate regions and estimation of absolute $\mathrm{CD}^{+}$numbers was derived from the total lymphocyte count. Side scatter versus FL2 (CD14-PE) dot plots were used to gate on the monocyte population. Histogram plots of cells incubated with the APC labelled IgG isotype control antibody alone (FL4) were used to define the threshold of positive staining for GHS-R1a on lymphocytes, CD3+ and CD14+ cells. Histogram plots of the cells in the lymphocyte, CD3+ and CD14+ regions that positively expressed GHS-R1a conjugated to the secondary antibody IgG-APC (FL4) were subsequently used to calculate the percentage of that cell subpopulation expressing GHS-R1a. Estimations of the concentration of circulating lymphocyte, $\mathrm{CD}^{+} \mathrm{T}$ cells and CD14+ monocytes expressing GHS-R1a were then calculated from the circulating cell counts. Geometric mean fluorescent intensity (GMFI), an indicator of the density of GHS-R1a expression on each cell, was also determined for lymphocytes, CD3+ T cells and CD14+ monocytes.

\section{Plasma acylated ghrelin concentration}


Blood collected into the final tube was used for the determination of acylated ghrelin concentration, according to Broom et al. (2007). This tube contained EDTA and phydroxymercuribenzoic acid to prevent the degradation of acylated ghrelin by protease. The samples were subsequently spun at $1500 \mathrm{~g}$ for $10 \mathrm{~min}$ in a refrigerated centrifuge at $4^{\circ} \mathrm{C}$. Supernatants were separated into eppendorf tubes and $100 \mu \mathrm{l}$ of 1M HCL were added per ml of plasma. Samples were spun in a refrigerated centrifuge at $1500 \mathrm{~g}$ for a further $5 \mathrm{~min}$ at $4^{\circ} \mathrm{C}$. Supernatants were separated into eppendorf tubes and stored at $-80^{\circ} \mathrm{C}$ for later analysis. Plasma acylated ghrelin concentrations were determined by commercially available ELISA, according to the manufacturer's instructions (SPI BIO, Montigny le Bretonneux, France). To eradicate interassay variation, samples from each participant were analysed in the same run. The intra-assay coefficient of variation was 3.3\%. Data are presented for 8 participants; due to a problem with the p-hydroxymercuribenzoic acid preservative in the samples from 1 participant.

\section{Comparison with sedentary participants}

Sedentary participants arrived at the laboratory at 09:45, following an overnight fast of at least $10 \mathrm{~h}$ and having avoided caffeine, alcohol and strenuous exercise during the previous 24 h. After sitting quietly for $10 \mathrm{~min}$, a single blood sample was collected from a superficial forearm vein. Participants were then free to leave the laboratory. GHS-R1a analysis on total lymphocytes, CD3+ T cells and CD14+ monocytes was performed as above.

\section{Statistical Analysis.}

Data in the text, tables and figures are presented as mean values and their standard deviation ( \pm SD). The data were examined using a two-factor (trial $x$ time) analysis of variance (ANOVA) with repeated measures design. Assumptions of sphericity were checked and, 
where appropriate, the adjustments to the degrees of freedom for the ANOVA were made using the Huynh-Feldt method of correction. Any significant $F$ ratios subsequently shown were assessed using Student's paired t-test to determine which values were significantly different with the Bonferroni correction for multiple comparisons applied to the unadjusted $p$ value. Effect sizes (ES) based on eta $^{2}$ are provided for all significant data to give an indication of the proportion of the variation attributable to trial or group, using Cohen's definition of eta ${ }^{2}$ of $0.01,0.06$ and 0.14 representing 'small', 'medium' and 'large' effects, respectively (Cohen, 1988). Comparisons between active and sedentary participants were assessed using the first sample from the active participants' resting trials with the independent t-test applied. Comparison of the area under the curve for the ghrelin values was assessed using the paired-samples t-test. Statistical significance was accepted at $p<.05$. All results were analysed using Statistical Software Package for Social Sciences (SPSS) software version 20.0 for Windows (SPSS, Chicago, IL).

\section{RESULTS}

Physiological responses to exercise

Mean \% $\dot{\mathrm{V}}_{2 \text { peak }}$ during EX was $73.1 \pm 3.7 \%$, mean heart rate was $168 \pm 7$ beats.min ${ }^{-1}$ and mean RPE was $16 \pm 1$. After exercise the mean decrease in body mass (corrected for fluid intake) was $1.1 \pm 0.2 \mathrm{~kg}$. There was no significant time $\mathrm{x}$ trial interaction effect for changes in plasma volume relative to the first blood sample; after exercise plasma volume had decreased by $5.7 \pm 3.4 \%$ and had decreased by $0.5 \pm 5.3 \%$ at the equivalent point in REST.

\section{Total lymphocytes}

There was a significant interaction between trial and time for the concentration of circulating lymphocytes (interaction, $F_{(3,24)}=10.0, p=.001$, ES $=0.56$; Table 1 ). At post-exercise in $\mathrm{EX}$, concentrations were higher than at the equivalent time in $\operatorname{REST}(p<.01)$ and lower at $2 \mathrm{~h}$ 
post-exercise than at the equivalent time in $\operatorname{REST}(p<.05)$. There was a significant interaction between trial and time for the concentration of lymphocytes expressing GHS-R1a (interaction $F_{(3,24)}=8.2, p=.001, \mathrm{ES}=0.51$; Figure 1). Concentrations were higher in EX at post-exercise, $1 \mathrm{~h}$ and $2 \mathrm{~h}$ post-exercise than in REST at the equivalent time points $(p<.01$, $p<.05$ and $p<.05$, respectively). There was a significant interaction between trial and time for the proportion of lymphocytes expressing GHS-R1a (interaction $F_{(3,24)}=5.8, p=.029$, ES = 0.42; Table 1). Values were higher in $\mathrm{EX}$ at $1 \mathrm{~h}$ and $2 \mathrm{~h}$ post-exercise than at the equivalent times in REST ( $p<.01$ and $p<.05$, respectively). There was no significant trial $\mathrm{x}$ time interaction or main effects for trial or time evident for the GMFI of GHS-R1a on lymphocytes (Table 1).

CD3+ T cells

There was a significant interaction between trial and time for the concentration of CD3+ T cells (interaction, $F_{(3,24)}=10.1, p=.001$, ES $=0.59$; Table 1). At post-exercise in EX, CD3+ concentration was higher than at the equivalent time in $\operatorname{REST}(p<.02)$. At 2 h postexercise CD3+ concentration was lower than at the equivalent time in REST $(p<.05)$. There was a significant interaction between trial and time for the concentration of CD3+ $\mathrm{T}$ cells expressing GHS-R1a (interaction $F_{(3,24)}=8.9, p=.007$, ES $=0.53$; Figure 2), with concentrations higher in EX at post-exercise than at the equivalent time point in REST ( $p$ $<.02)$. Similarly, there was a significant interaction between trial and time for the proportion of CD3+ T cells expressing GHS-R1a (interaction $F_{(3,24)}=6.4, p=.002$, $\mathrm{ES}=0.45$; Table 1 ); values were also higher in EX immediately post-exercise than at the equivalent times in REST $(p<.01)$. There was no significant trial $\mathrm{x}$ time interaction or main effects for trial or time evident for the GMFI of GHS-R1a on CD3+ T cells (Table 1). 
There was a significant interaction between trial and time for the concentration of CD14+ monocytes (interaction, $F_{(3,24)}=3.1, p=.047$, ES $=0.28$; Table 1). Circulating CD14+ monocyte concentration was higher in EX at $1 \mathrm{~h}$ and $2 \mathrm{~h}$ post-exercise than at the equivalent time points in REST (both $p<.01$ ). There was a significant interaction between trial and time for the concentration of CD14+ monocytes expressing GHS-R1a (interaction $F_{(3,24)}=$ 4.1, $p=.018, \mathrm{ES}=0.34$; Figure 3), with concentrations higher in EX at immediately, $1 \mathrm{~h}$ and $2 \mathrm{~h}$ post-exercise than in REST at the equivalent time points $(p<.02, p<.01, p<.02$, respectively). Similarly, there was a significant interaction between trial and time for the proportion of CD14+ monocytes expressing GHS-R1a (interaction $F_{(3,24)}=4.1, p=.030$, ES $=0.34$; Table 1), with values higher in EX at $1 \mathrm{~h}$ and $2 \mathrm{~h}$ post-exercise than at the equivalent times in $\operatorname{REST}(p<.05$ and $p<.01$, respectively). There was no significant trial $\mathrm{x}$ time interaction or main effects for trial or time evident for the GMFI of GHS-R1a on CD14+ monocytes (Table 1).

\section{Plasma acylated ghrelin concentration}

There was a significant trial $\mathrm{x}$ time interaction effect $\left(F_{(3,21)}=6.8, p=.002\right.$, ES $\left.=0.50\right)$ for plasma acylated ghrelin concentration, with values significantly lower at immediately and $1 \mathrm{~h}$ post-exercise in EX compared with the equivalent time points in $\operatorname{REST}(p<.001$ and $p<.05$, respectively) (Figure 4). Area under the curve for plasma acylated ghrelin concentrations was lower in EX than REST (199 \pm 71 pg.ml ${ }^{-1} .3$ h vs. $338 \pm 136$ pg.ml $^{-1} .3 \mathrm{~h}, t(7)=4.32, p<$ $.01, \mathrm{ES}=0.70)$.

\section{Comparison between active and sedentary participants at rest}

Median IPAQ activity scores were 3173 (range 1158-4812) MET-min.week ${ }^{-1}$ in the active participants and 317 (range 132-436) MET-min.week ${ }^{-1}$ in the sedentary participants. IPAQ 
guidelines define a low activity score as less than 600 MET-min.week $^{-1}$. In the active group, activity was equivalent to approximately $3 \mathrm{~h}$ of vigorous and $3 \mathrm{~h}$ of moderate activity per week. There were no significant differences between the active and sedentary participants for circulating cell counts, proportion of monocytes and T cells expressing GHS-R1a and the density of GHS-R1a expression on lymphocytes, T cells and monocytes (Table 1). However the proportion of lymphocytes expressing GHS-R1a was higher in active compared with sedentary participants $(t(14)=2.21, p<.05$, ES $=0.26$, respectively, Table 1$)$. The concentration of lymphocytes expressing GHS-R1a was also higher in active participants $\left(234 \pm 130\right.$ cells. $\mu 1^{-1}$ vs. $93 \pm 76$ cells. $\left.\mu 1^{-1}, t(14)=2.53, p<.05, \mathrm{ES}=0.35\right)$, but there were no differences in the concentration of CD3+GHS-R1a+ cells $\left(59 \pm 38\right.$ cells. $\mu l^{-1}$ vs. $73 \pm 67$ cells. $\left.\mu \mathrm{l}^{-1}\right)$ and CD14+GHS-R1a+ cells $\left(50 \pm 22\right.$ cells. $\mu \mathrm{l}^{-1}$ vs. $65 \pm 14$ cells. $\left.\mu \mathrm{l}^{-1}\right)$ between the active and sedentary groups.

\section{DISCUSSION}

The principal finding of the present study was that an acute bout of strenuous exercise was associated with an increase in both the concentration and proportion of total lymphocytes, CD3+ T cells and CD14+ monocytes expressing the specific receptor for acylated ghrelin, GHS-R1a, yet the density of receptor expression was unaffected by exercise. We also report higher GHS-R1a expression on lymphocytes at rest in the active males compared with a group of age-, sex-, and BMI-matched sedentary counterparts.

To the authors' knowledge, this study is the first to show a substantial effect of exercise on the circulating proportion and concentration of lymphocytes, $\mathrm{T}$ cells and monocytes expressing GHS-R1a. The fact that the density of expression of the receptor on each cell type was unchanged by exercise suggests that the increase is related to a preferential recruitment of cells with a propensity for GHS-R1a expression, rather than any up regulation of receptor 
expression per se. We chose to assess the GHS-R1a response to exercise chiefly on $\mathrm{T}$ cell and CD14+ monocytes because the ability of ghrelin to attenuate pro-inflammatory cytokine release from PBMCs is dependent on the availability of this specific receptor (Dixit et al., 2004). Future investigations should determine which of the recruited CD3+ and CD14+ subsets are expressing GHS-R1a. It seems plausible that the subpopulations that are more metabolically and inflammation-active will have higher expression, i.e. CD16+ monocytes and the effector memory and senescent CD45RA+ effector memory CD8+ $\mathrm{T}$ cell subpopulations (Appay et al., 2008; Ziegler-Heitbrock et al., 2010). Of particular note, responses in CD3+ T cells did not fully account for the expression of GHS-R1a observed in total lymphocytes. GHS-R1a is also expressed on human B lymphocytes and NK cells (Hattori et al., 2001, Taub et al., 2010), therefore it is likely that an increase in GHS-R1a+ NK cells and B cells contributed to the total lymphocyte response. In particular, acylated ghrelin is reported to exert potent inhibitory effects on the mRNA and protein expression of IL-1 $\beta$ and TNF- $\alpha$ by NK cells in vitro (Taub et al., 2010).

The recruitment of lymphocytes and monocytes into the circulation is largely related to adrenergic-mediated demargination and extravasation of sequestered cells (Shephard, 2003; Kruger et al. 2008), with cell subpopulations that are selectively deployed in response to an exercise stimulus also being those with the greatest expression of $\beta 2$-adrenoreceptors or with greatest affinity for epinephrine (Shephard, 2003; Dimitrov et al., 2010). These recruited cells appear also to be those with potent effector/cytotoxic functions whereas those that preferentially transmigrate into the tissues have tissue migratory phenotypes (Simpson et al., 2008; Turner et al., 2010). In this way there appears to be a selective deployment of specific cell subpopulations that are deemed most able to respond effectively to an immune/inflammatory challenge (Dhabhar, 2009). Taking this view in the context of the present study, enhanced recruitment of GHS-R1a+ monocytes and lymphocytes with acute 
exercise implies that these subpopulations have a high expression of $\beta 2$-adrenoreceptors and potentially provides a circulating population of cells with high anti-inflammatory potential available for tissue migration. Indeed, numbers of GHS-R1a+ T cells peaked immediately after exercise and returned to baseline values within the first hour after exercise, whereas the concentration of total lymphocytes expressing GHS-R1a remained above that in REST even at $2 \mathrm{~h}$ post-exercise. While this may indicate remargination of the GHS-R1a+ $\mathrm{T}$ cell subpopulation, it may also suggest preferential migration of this specific subpopulation into the tissues. In support for this, GHS-R1a ligation in human T cells is associated with actin polymerisation and actin distribution changes consistent with a role in cell signalling and trafficking (Dixit et al., 2004).

The finding of higher concentrations and proportion GHS-R1a+ lymphocytes in active compared with sedentary participants at rest also supports a role of GHS-R1a in the reduction of circulating pro-inflammatory cytokines in regularly active individuals. While this finding needs to be confirmed in a larger cohort, elevated numbers of circulating lymphocytes expressing GHS-R1a at rest may represent a chronic adaptation to successive acute exercise bouts whereby a population of cells that are best adapted to respond quickly to inflammation, illness or injury are preferentially deployed (Dhabhar, 2009).

Immune cell expression of GHS-R1a declines with age and has been related to age-associated thymic involution and increased levels of systemic inflammation (Dixit and Taub, 2005; Dixit et al., 2009). Indeed ghrelin and GHS-R1a knockout mice exhibit reduced thymocyte counts and more pronounced age-dependent thymic involution than in wild type mice (Dixit et al., 2007). Ghrelin expression by $\mathrm{T}$ cells is also reduced in ageing mice and ghrelin infusion in this model has been shown to reduce levels of IL-6, TNF- $\alpha$ and IL-1 $\beta$ (Dixit et al., 2009). Ghrelin infusion to improve lean body mass and appetite and decrease circulating inflammatory cytokines has had positive outcomes in patient populations with inflammation- 
related cachexia including cachetic cancer, cardiovascular disease, chronic obstructive pulmonary disease and chronic kidney disease (DeBoer, 2011; DeBoer et al., 2008; Nagaya et al., 2004, 2005; Strasser et al., 2008). Our finding of increased GHS-R1a availability after exercise and a higher circulating proportion and concentration of GHS-R1a+ lymphocytes in active compared with sedentary individuals suggests that exercise prescription should be explored further as a tool to enhance the effectiveness of ghrelin therapy. Ghrelin is reported to be safe and well tolerated at doses of up to $10 \mu \mathrm{g} \cdot \mathrm{kg}^{-1}$ (total ghrelin, Nagaya et al., 2001; Strasser et al., 2008) and $5 \mu \mathrm{g} . \mathrm{kg}^{-1}$ (acylated form; Akamizu et al., 2004) in both patient populations and healthy individuals with plasma concentrations of acylated ghrelin increasing by at least 30-fold after administration to around 3000-4000 pg.ml ${ }^{-1}$ (3-4 ng.ml ${ }^{-1}$ ) (Akamizu et al., 2004). Adverse effects of ghrelin administration are seemingly few; reports of shortlasting (minutes) and relatively mild abdominal discomfort and flushing are common and increases in plasma glucose and decreases in plasma insulin levels are also reported (Akamizu et al., 2004; Strasser et al., 2008). However, there are still unanswered questions concerning the effect of long-term ghrelin administration on growth hormone-mediated stimulation of tumour growth and there is the potential for ghrelin resistance with high plasma levels over a long period of time (Strasser et al., 2008). In this regard and considering the increased availability of GHS-R1a with exercise, future in vitro work should determine whether the concentration of acylated ghrelin required to elicit inhibitory effects on $\mathrm{T}$ cell and monocyte inflammatory cytokine release is lower after acute exercise or in active compared with sedentary individuals at rest.

In the present study, plasma levels of acylated ghrelin were temporarily suppressed after acute exercise, in accordance with previous literature (Broom et al., 2007; King et al., 2010). The reasons for this fall are unclear, but are thought to be related to reduced blood flow to the splanchnic regions with exercise (King et al., 2013). This could interfere directly in the 
release of acylated ghrelin into the circulation or reduce oxygen supply thus affecting the ability of ghrelin to become acylated via actions on ghrelin O-acyltransferase activity within the Golgi apparatus. Additionally augmented de-acylation by circulating proteases/esterases may also be involved (King et al., 2013). While there is no evidence to suggest that ghrelin directly regulates GHS-R1a expression, it could be argued that this limits the availability of ghrelin to bind to GHS-R1a on peripheral immune cells and exert its inhibitory effect on proinflammatory cytokine release, regardless of the exercise-associated increases in GHS-R1a+ PBMCs found here. Although the effect of post-exercise ghrelin levels on PBMC cytokine release was not assessed here (and was not the focus of the study), it should be noted that plasma acylated ghrelin levels had returned to baseline levels at $2 \mathrm{~h}$ post-exercise, whereas the impact of exercise on GHS-R1a expression persisted for monocytes and lymphocytes at this time. Therefore, any negative influence would be relatively short-lived. In the present study circulating concentrations of acylated ghrelin fell to $\sim 40$ pg.ml ${ }^{-1}\left(0.04\right.$ ng.ml $l^{-1}$ ) after acute exercise. In vitro inhibition of $\mathrm{T}$ cell and monocyte cytokine production via ligation with GHS-R1a is reported at concentrations ranging from 1-1000 ng.ml ${ }^{-1}$ (Dixit et al., 2004; Waseem et al, 2008). The effect of acylated ghrelin at concentrations of less than $1 \mathrm{ng} \cdot \mathrm{ml}^{-1}$ has not been determined. However, both acylated and des-acylated ghrelin are also secreted by human monocytes and $\mathrm{T}$ cells, with secretion increasing rapidly upon activation and peaking after 48 h (Hattori et al., 2001, Dixit et al., 2004; Dixit et al., 2009). The amount secreted is not insignificant; activated T cells can produce between 300 and 800 pg.ml ${ }^{-1}$ of total ghrelin upon activation and can also express the pre-pro form of ghrelin in their Golgi bodies, where it is presumably cleaved to its mature form (Dixit et al., 2004). This suggests that ghrelin acts to regulate cell function within the immune microenvironment in an autocrine/paracrine manner. Acute exercise is also known to activate T cells and monocytes (Woods et al., 2000; Walsh et al., 2011) and thus it may be speculated to stimulate ghrelin 
secretion by PBMCs to act locally; this requires confirmation. Circulating acylated ghrelin also has a half-life of just 9-13 min (Akamizu et al., 2004). For these reasons, it is proposed that ghrelin concentrations are able to reach biologically high levels within the local microenvironment that are not restricted by circulating concentrations (Dixit et al., 2004). Taken together, the current literature suggests that reductions in plasma concentrations of acylated ghrelin after exercise will not necessarily compromise ghrelin availability in the immune microenvironment.

In summary, the present study is the first to demonstrate the preferential recruitment of peripheral circulating lymphocytes, $\mathrm{T}$ cells and monocytes expressing GHS-R1a in response to acute exercise and higher concentrations of GHS-R1a+ lymphocytes in active compared with sedentary young, healthy males at rest. Given that the established inhibitory effects of acylated ghrelin on pro-inflammatory cytokine expression are dependent on GHS-R1a expression, these findings suggest that GHS-R1a expression may be an additional avenue by which exercise exerts anti-inflammatory effects. Furthermore, these findings have substantial implications for the use of exercise prescription to augment the promising therapeutic effects of exogenous ghrelin and ghrelin mimetics in the treatment of long-term inflammatory illnesses and age-associated inflammation. Future work needs to determine optimal exercise prescription in both clinical and healthy older populations to maximise GHS-R1a expression on inflammatory immune cells.

\section{REFERENCES}

Akamizu, T., Takaya, K., Irako, T., Hosoda, H., Teramukai, S., Matsuyama, A., Tada, H., Miura, K., Shimizu, A., Fukushima, M., Yokode, M., Tanaka, K., Kangawa, K., 2004. Pharmacokinetics, safety, and endocrine and appetite effects of ghrelin administration in young healthy subjects. Eur. J. Endocrinol. 150, 447-455. 
Appay, V., van Lier, R.A., Sallusto, F., Roederer, M., 2008. Phenotype and function of human T lymphocyte subsets: consensus and issues. Cytometry A. 73, 975-983.

Baatar, D., Patel, K., Taub, D.D., 2011. The effects of ghrelin on inflammation and the immune system. Mol. Cell. Endocrinol. 340, 44-58.

Broom, D.R., Stensel, D.J., Bishop, N.C., Burns, S.F., Miyashita, M., 2007. Exerciseinduced suppression of acylated ghrelin in humans. J. Appl. Physiol. 102, 2165-2171.

Cohen, J. 1988. Statistical Power Analysis for the Behavioral Sciences (2nd ed.), Lawrence Erlbaum Associates, Hillsdale, NJ, pp. 284-287.

Craig, C.L., Marshall, A.L., Sjostrom, M., Bauman, A.E., Booth, M.L., Ainsworth, B.E., Pratt, M., Ekelund, U., Yngve, A., Sallis, J.F., Oja, P., 2003. International physical activity questionnaire: 12-country reliability and validity. Med Sci Sports Exerc 35, 1381-1395.

DeBoer, M.D., 2011. Ghrelin and cachexia: will treatment with GHSR-1a agonists make a difference for patients suffering from chronic wasting syndromes? Mol. Cell. Endocrinol. 340, 97-105.

DeBoer, M.D., Zhu, X., Levasseur, P.R., Inui, A., Hu, Z., Han, G., Mitch, W.E., Taylor, J.E., Halem, H.A., Dong, J.Z., Datta, R., Culler, M.D., Marks, D.L., 2008. Ghrelin treatment of chronic kidney disease: improvements in lean body mass and cytokine profile. Endocrinology 149, 827-835.

Dhabhar, F.S., 2009. Enhancing versus suppressive effects of stress on immune function: implications for immunoprotection and immunopathology. Neuroimmunomodulation 16, $300-317$. 
Dill, D.B., Costill, D.L., 1974. Calculation of percentage changes in volumes of blood, plasma, and red cells in dehydration. J. Appl. Physiol. 37, 247-248.

Dimitrov, S., Lange, T., Born, J., 2010. Selective mobilization of cytotoxic leukocytes by epinephrine. J. Immunol. 184, 503-511.

Dixit, V.D., Taub, D.D., 2005. Ghrelin and immunity: a young player in an old field. Exp Gerontol. 40, 900-910.

Dixit, V.D., Schaffer, E.M., Pyle, R.S., Collins, G.D., Sakthivel, S.K., Palaniappan, R., Lillard Jr., J.W., Taub, D.D., 2004. Ghrelin inhibits leptin- and activation induced proinflammatory cytokine expression by human monocytes and T-cells. J. Clin. Invest.114, 57-66.

Dixit, V.D., Yang, H., Cooper-Jenkins, A., Giri, B.B., Patel, K., Taub, D.D., 2009. Reduction of T cell-derived ghrelin enhances proinflammatory cytokine expression: implications for age-associated increases in inflammation. Blood. 113, 5202-5205.

Dixit, V.D., Yang, H., Sun, Y., Weeraratna, A.T., Youm, Y.H., Smith, R.G., Taub, D.D. 2007. Ghrelin promotes thymopoiesis during aging. J. Clin. Invest. 117, 2778-2790.

Gleeson, M., Bishop, N.C., Stensel, D.J., Lindley, M.R., Mastana, S.S., Nimmo, M.A., 2011. The anti-inflammatory effects of exercise: mechanisms and implications for the prevention and treatment of disease. Nature Rev. Immunol., 11, 1-9.

Hatttori, N., Saito, T., Yagyu, T., Jiang, B.H., Kitagawa, K., Inagaki, C., 2001. GH, GH receptor, GH secretagogue receptor, and ghrelin expression in human T cells, B cells and neutrophils. J. Clin. Endocrinol. Metab., 86, 4284-4291. 
Karalis, K.P., Giannogonas, P., Kodela, E., Koutmani, Y., Zoumakis, M., Teli, T., 2009.

Mechanisms of obesity and related pathology: linking immune responses to metabolic stress. FEBS J. 276, 5747-5754.

Kelley, K.W., Bluthé, R.M., Dantzer, R., Zhou, J.H., Shen, W.H., Johnson, R.W., Broussard, S.R., 2003. Cytokine-induced sickness behavior. Brain Behav. Immun. 17 Suppl 1:S112-118.

King, J.A., Miyashita, M., Wasse, L.K., Stensel, D.J., 2010. Influence of prolonged treadmill running on appetite, energy intake and circulating concentrations of acylated ghrelin. Appetite, 54, 492-498.

King, J.A., Wasse, L.K., Stensel, D.J., Nimmo, M.A. 2013. Exercise and ghrelin. A narrative overview of research. Appetite, 68, 83-91.

Kruger, K., Lechtermann, A., Fobker, M., Volker, K., Mooren, F.C., 2008. Exercise-induced redistribution of $\mathrm{T}$ lymphocytes is regulated by adrenergic mechanisms. Brain Behav. Immun. 22: 324-338.

Nagaya, N., Kojima, M., Uematsu, M., Yamagishi, M., Hosoda, H., Oya, H., Hayashi, Y., Kangawa, K., 2001. Hemodynamic and hormonal effects of human ghrelin in healthy volunteers. Am. J. Physiol. Regul. Integr. Comp. Physiol. 280, R1483-1487.

Nagaya, N., Moriya, J., Yasumura, Y., Uematsu, M., Ono, F., Shimizu, W., Ueno, K., Kitakaze, M., Miyatake, K., Kangawa, K., 2004. Effects of ghrelin administration on left ventricular function, exercise capacity, and muscle wasting in patients with chronic heart failure. Circulation 110, 3674-3679.

Nagaya, N., Itoh, T., Murakami, S., Oya, H., Uematsu, M., Miyatake, K., Kangawa, K., 2005. Treatment of cachexia with ghrelin in patients with COPD. Chest 128, 1187-1193. 
Odegaard, J.I., Chawla, A., 2013. The immune system as a sensor of the metabolic state. Immunity 38, 644-654.

Shephard, R.J., 2003. Adhesion molecules, catecholamines and leucocyte redistribution during and following exercise. Sports Med. 33, 261-284.

Simpson, R.J., Cosgrove, C., Ingram, L.A., Florida-James, G.D., Whyte, G.P., Pircher, H., Guy, K., 2008. Senescent T-lymphocytes are mobilised into the peripheral blood compartment in young and older humans after exhaustive exercise. Brain Behav. Immun 22, $544-551$.

Steinman, J., DeBoer, M.D., 2013. Treatment of cachexia: melanocortin and ghrelin interventions. Vitam Horm. 92,197-242.

Strasser, F., Lutz, T.A., Maeder, M.T., Thuerlimann, B., Bueche, D., Tschöp, M., Kaufmann, K., Holst, B., Brändle, M., von Moos, R., Demmer, R., Cerny, T. 2008. Safety, tolerability and pharmacokinetics of intravenous ghrelin for cancer-related anorexia/cachexia: a randomised, placebo-controlled, double-blind, double-crossover study. Br. J. Cancer. 98, 300-308.

Taub, D.D., Murphy J.M., Longo, D.L., 2010. Rejuvination of the aging thymus: growth hormone-mediated and ghrelin-kediated signalling pathways. Curr. Opin. Pharmacol. 10, 408-424.

Turner, J.E., Aldred, S., Witard, O.C., Drayson, M.T., Moss, P.M., Bosch, J.A., 2010. Latent cytomegalovirus infection amplifies CD8 T-lymphocyte mobilisation and egress in response to exercise. Brain Behav. Immun. 24, 1362-1370. 
Walsh, N.P., Gleeson, M., Shephard, R.J., Woods, J.A., Bishop, N.C., Fleshner, M., Green C, Pedersen, B.K., Hoffman-Goetz, L., Rogers, C.J., Northoff, H., Abbasi, A., Simon, P., 2011. Position Statement Part One: Immune Function and Exercise. Exerc. Immunol. Rev. 17, 6-63. Waseem, T., Duxbury, M., Ito, H., Ashley, S.W., Robinson, M.K. 2008. Exogenous ghrelin modulates release of pro-inflammatory and anti-inflammatory cytokines in LPS-stimulated macrophages through distinct signalling pathways. Surgery 143, 334-342.

Woods, J., Lu, Q., Ceddia, M.A., Lowder, T., 2000. Special feature for the Olympics: effects of exercise on the immune system: exercise-induced modulation of macrophage function. Immunol. Cell. Biol.78, 545-553.

Ziegler-Heitbrock, L., Ancuta, P., Crowe, S., Dalod, M., Grau, V., Hart, D.N., Leenen, P.J., Liu, Y.J., MacPherson, G., Randolph, G.J., Scherberich, J., Schmitz, J., Shortman, K., Sozzani, S., Strobl, H., Zembala, M., Austyn, J.M., Lutz, M.B., 2010. Nomenclature of monocytes and dendritic cells in blood. Blood 116, e74-e80. 


\section{Figure legends}

Figure 1. Concentration of circulating lymphocytes expressing GHS-R1a in response to $1 \mathrm{~h}$ cycling at $75 \% \dot{\mathrm{V}} \mathrm{O}_{2 \text { peak }}(\mathrm{EX})$ or rest $(\mathrm{REST})$. Values are means $\pm \mathrm{SD}, \mathrm{n}=9$. Significantly higher than REST at that time, *, $p<.05$; **, $p<0.01$. Significantly higher than at preexercise (within trial), $\dagger, p<.01$.

Figure 2. Concentration of circulating $\mathrm{T}$ cells expressing GHS-R1a in response to $1 \mathrm{~h}$ cycling at $75 \% \dot{\text { VOO }}$ 2peak $(E X)$ or rest (REST). Values are means $\pm S D, n=9$. Significantly higher than REST at that time, ${ }^{*}, p<.05$. Significantly higher than at pre-exercise (within trial), $\dagger$, $p<.05$

Figure 3. Concentration of circulating CD14+ monocytes expressing GHS-R1a in response to $1 \mathrm{~h}$ cycling at $75 \% \dot{\mathrm{V}} \mathrm{O}_{2 \text { peak }}(\mathrm{EX})$ or rest $(\mathrm{REST})$. Values are means $\pm \mathrm{SD}, \mathrm{n}=9$. Significantly higher than REST at that time, ${ }^{*}, p<.05 ; * *, p<.01$.

Figure 4. Plasma acylated ghrelin concentration in response to 1 h cycling at $75 \% \dot{\mathrm{V}} \mathrm{O}_{2 \text { peak }}$ (EX) or rest (REST). Values are means $\pm S D, n=8$. Significantly lower than REST at that time, ${ }^{*}, p<.05 ;{ }^{* *}, p<.01$. Significantly lower than at pre-exercise (within trial), $\dagger^{*}, p<.01$. Significantly higher than at 10:00 (within trial), $\dagger, p<.05$. 
Table 1. Lymphocyte, CD3+ T cell and CD14+ monocyte numbers, proportion of cells expressing the growth hormone secretagogue receptor (GHS-R1a) and the density of GHSR1a expression on each cell type in active participants after acute exercise (EX) and rest (REST) and in sedentary controls at rest.

\begin{tabular}{|c|c|c|c|c|}
\hline & $\begin{array}{l}\text { Pre-exercise } \\
(10: 00)\end{array}$ & $\begin{array}{l}0 \text { h post-exercise } \\
(11: 00)\end{array}$ & $\begin{array}{l}1 \mathrm{~h} \text { post-exercise } \\
(12: 00)\end{array}$ & $\begin{array}{l}2 \text { h post-exercise } \\
(13: 00)\end{array}$ \\
\hline \multicolumn{5}{|c|}{ Lymphocyte count $\left(\times 10^{9}\right.$ cells. $\left.^{-1}\right)$} \\
\hline EX & $1.98(0.33)$ & $2.64(0.71)^{\mathrm{a}, \mathrm{d}}$ & $1.67(0.44)$ & $1.62(0.29)^{\mathrm{b}, \mathrm{d}}$ \\
\hline REST & $1.90(0.32)$ & $1.91(0.30)$ & $1.79(0.48)$ & $1.86(0.30)$ \\
\hline SEDENTARY & $2.16(0.51)$ & & & \\
\hline \multicolumn{5}{|c|}{ Proportion of lymphocytes expressing GHS-R1a (\%) } \\
\hline EX & $10.4(2.9)$ & $19.0(4.6)$ & $26.0(12.0)^{\mathrm{a}, \mathrm{c}}$ & $17.3(10.2)^{\mathrm{b}, \mathrm{c}}$ \\
\hline REST & $15.4(11.8)$ & $12.0(12.8)$ & $8.3(4.1)$ & $9.4(7.5)$ \\
\hline SEDENTARY & $4.0(2.5)^{\mathrm{e}}$ & & & \\
\hline \multicolumn{5}{|c|}{ Density of GHS-R1a expression on total lymphocytes (GMFI) } \\
\hline $\mathrm{EX}$ & $48.3(20.2)$ & $52.2(21.2)$ & $49.6(12.1)$ & $45.7(17.8)$ \\
\hline REST & $57.5(19.1)$ & $60.1(19.0)$ & $53.8(15.3)$ & $57.4(25.7)$ \\
\hline SEDENTARY & $43.6(5.5)$ & & & \\
\hline \multicolumn{5}{|c|}{ CD3 + count $\left(\times 10^{9}\right.$ cells..$\left.^{-1}\right)$} \\
\hline $\mathrm{EX}$ & $1.20(0.20)$ & $1.58(0.45)^{\mathrm{b}, \mathrm{d}}$ & $1.05(0.30)$ & $0.98(0.17)^{\mathrm{b}, \mathrm{d}}$ \\
\hline REST & $1.19(0.24)$ & $1.19(0.19)$ & $1.11(0.28)$ & $1.18(0.21)$ \\
\hline SEDENTARY & $1.30(0.35)$ & & & \\
\hline \multicolumn{5}{|c|}{ Proportion of CD3+ cells expressing GHS-R1a (\%) } \\
\hline EX & $6.22(3.80)$ & $15.06(8.75)^{\mathrm{a}, \mathrm{c}}$ & $9.09(5.40)$ & $7.77(4.92)$ \\
\hline
\end{tabular}




\begin{tabular}{|c|c|c|c|c|}
\hline REST & $4.90(3.03)$ & $5.38(3.89)$ & $4.33(2.50)$ & $4.09(2.71)$ \\
\hline SEDENTARY & $3.14(3.4)$ & & & \\
\hline \multicolumn{5}{|c|}{ Density of GHS-R1a expression on CD3+ cells (GMFI) } \\
\hline EX & $50.0(20.3)$ & $54.5(21.1)$ & $56.9(12.2)$ & $43.1(16.5)$ \\
\hline REST & $62.5(24.7)$ & $63.8(21.0)$ & $56.4(15.6)$ & $60.6(26.1)$ \\
\hline SEDENTARY & $46.9(6.8)$ & & & \\
\hline \multicolumn{5}{|c|}{ Monocyte count $\left(\times 10^{9}\right.$ cells. $\left.l^{-1}\right)$} \\
\hline EX & $0.50(0.16)$ & $0.47(0.16)$ & $0.72(0.16)^{\mathrm{a}, \mathrm{d}}$ & $0.71(0.21)^{\mathrm{a}, \mathrm{c}}$ \\
\hline REST & $0.43(0.12)$ & $0.36(0.07)$ & $0.48(0.19)$ & $0.44(0.09)$ \\
\hline SEDENTARY & $0.46(0.15)$ & & & \\
\hline \multicolumn{5}{|c|}{ Proportion of CD14+ monocytes expressing GHS-R1a (\%) } \\
\hline EX & $12.9(7.7)$ & $22.6(13.8)^{b}$ & $16.3(9.4)^{\mathrm{a}}$ & $10.3(5.8)$ \\
\hline REST & $12.1(6.6)$ & $10.9(8.7)$ & $8.1(3.88)$ & $8.0(3.6)$ \\
\hline SEDENTARY & $16.8(6.2)$ & & & \\
\hline \multicolumn{5}{|c|}{ Density of GHS-R1a expression on CD14+ monocytes (GMFI) } \\
\hline EX & $45.9(15.5)$ & $44.5(15.6)$ & $39.3(9.0)$ & $38.0(13.0)$ \\
\hline REST & $53.5(17.9)$ & $52.2(15.5)$ & 46.9 (12.4) & $47.1(18.1)$ \\
\hline
\end{tabular}

SEDENTARY $48.7(20.2)$

Values are means (SD). GMFI; geometric mean fluorescence intensity

a , significantly different from REST at that time, $p<.01$

${ }^{\mathrm{b}}$ significantly different from REST at that time, $p<.05$

${ }^{\mathrm{c}}$ significantly different from pre-exercise values, $p<.01$

${ }^{\mathrm{d}}$ significantly different from pre-exercise values, $p<.05$

${ }^{\mathrm{e}}$ significantly different from REST at that time, $p<.05$ 
Figure 1

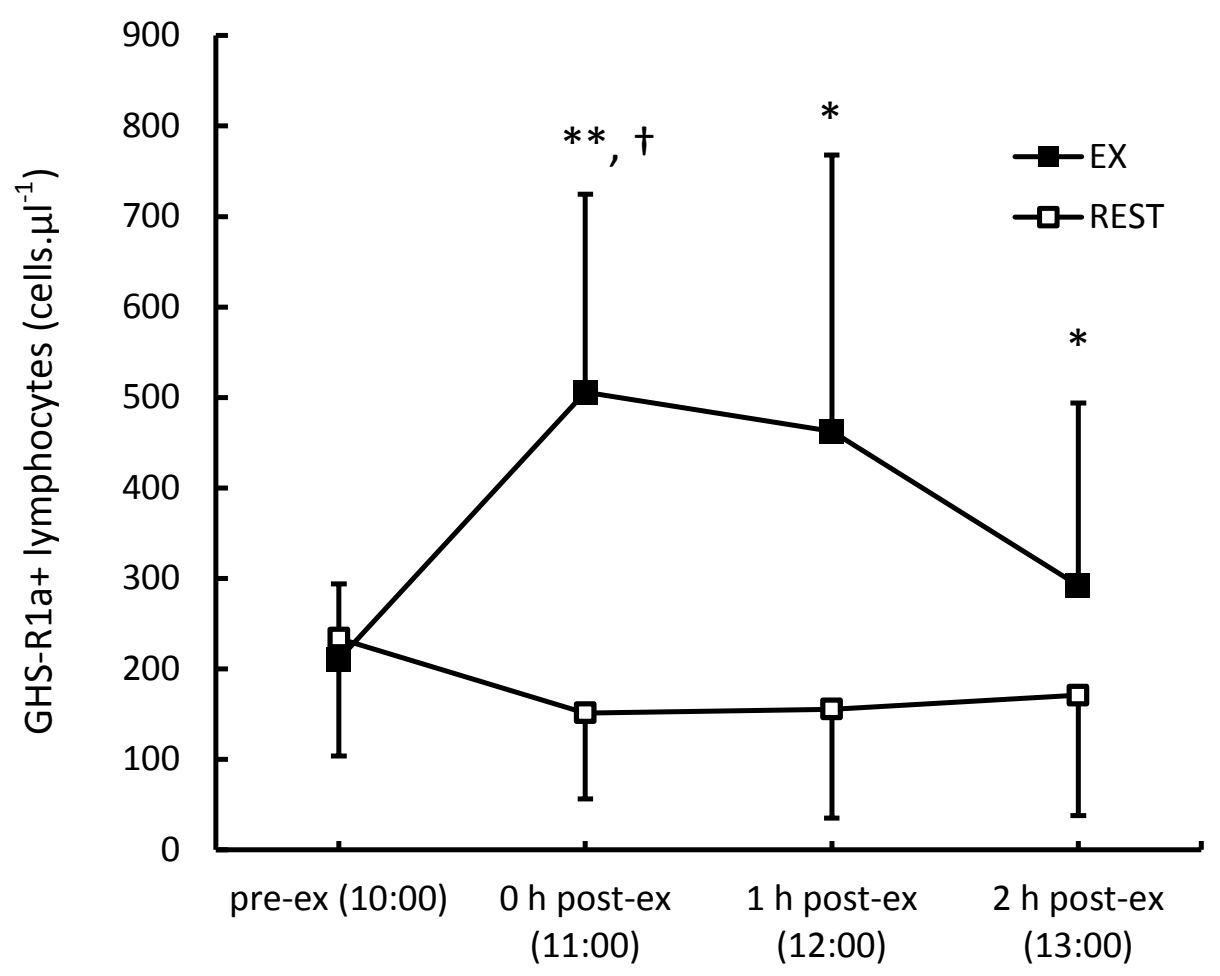


Figure 2

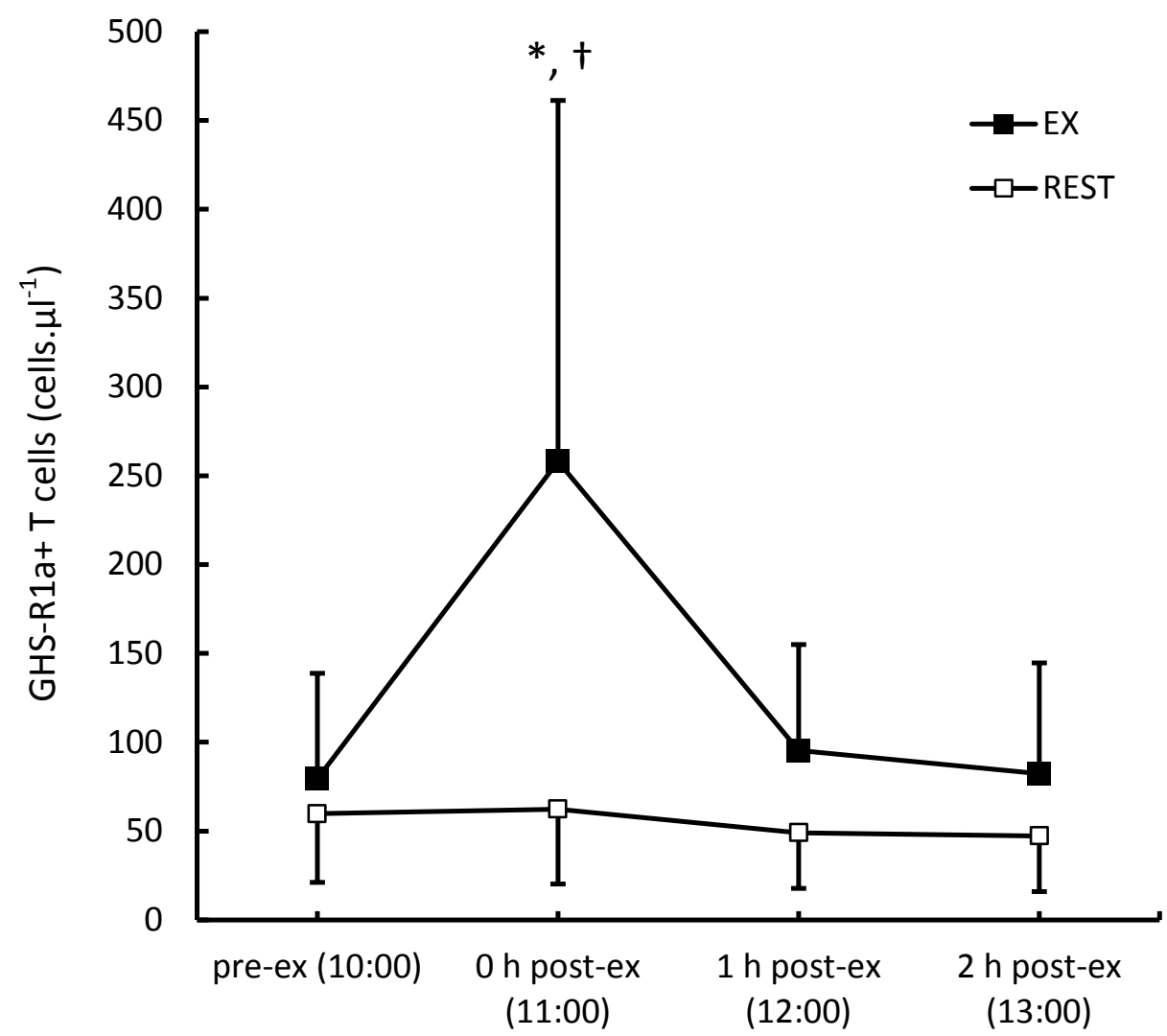


Figure 3

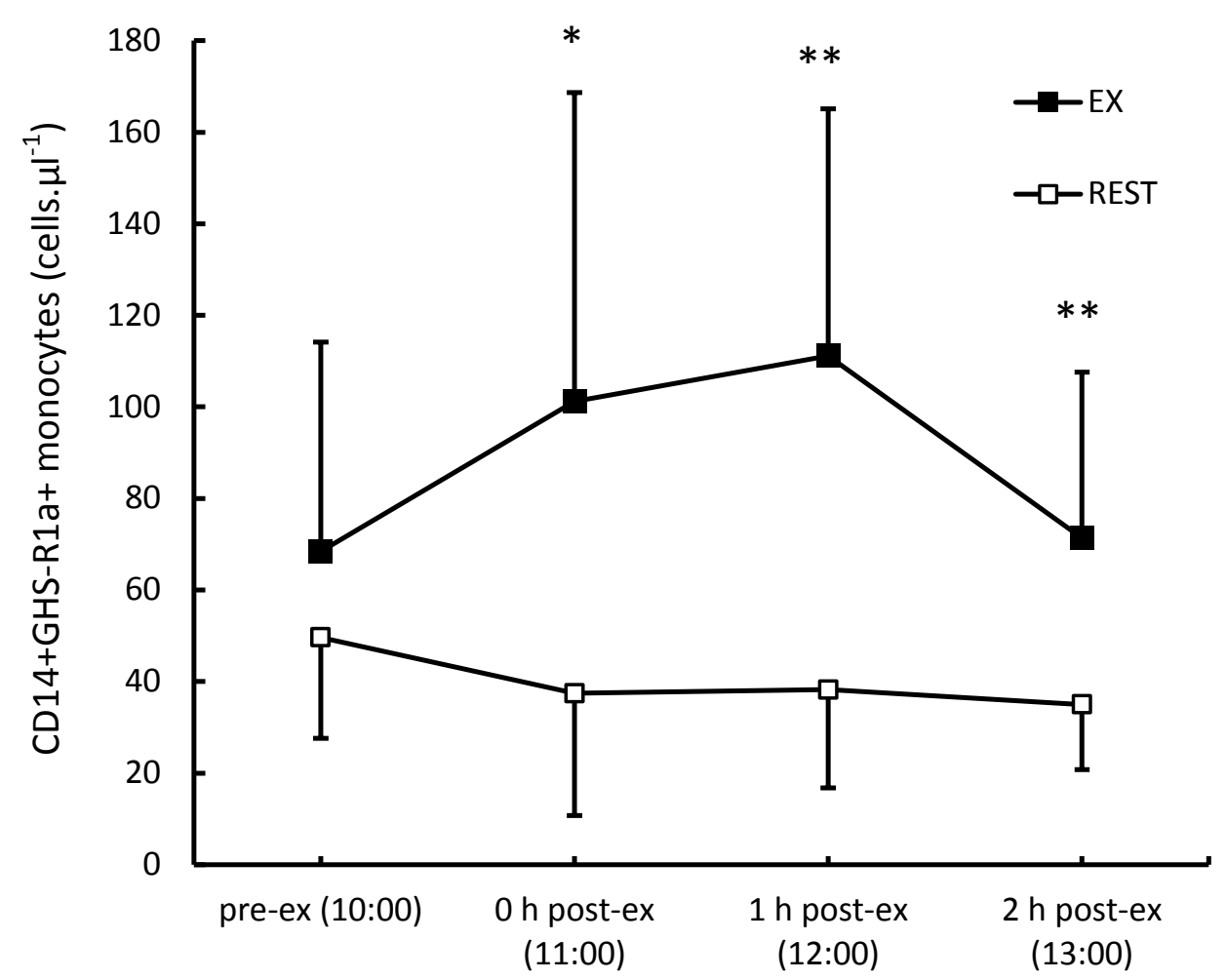


Figure 4

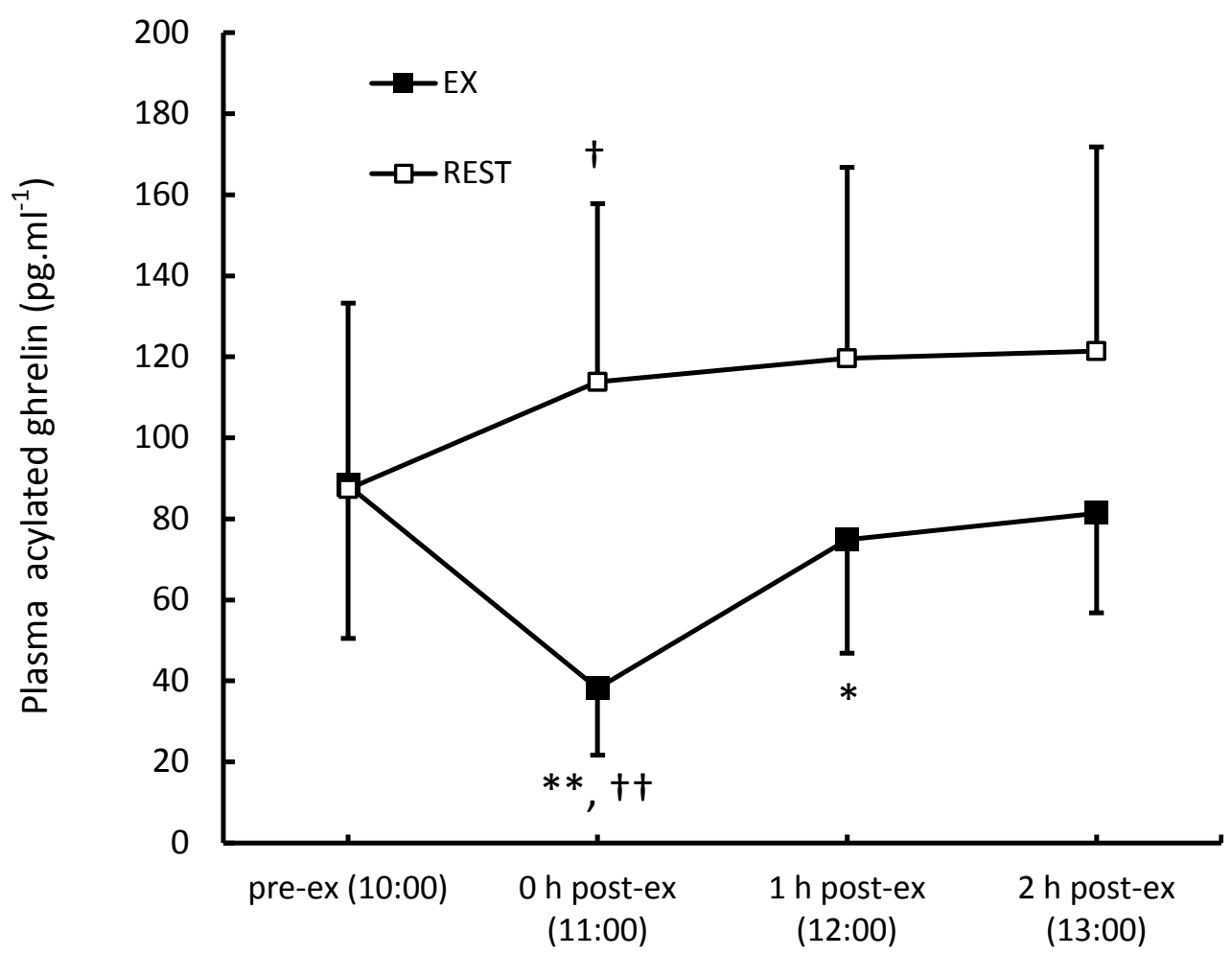

